\title{
ACRF Ingest Software Status: New, Current, and Future
}

Revision 5
A.S. Koontz
S. Choudhury
B.D. Ermold
N. N. Keck
K.L. Gaustad
R.C. Perez

March 2008

Work supported by the U.S. Department of Energy, Office of Science, Office of Biological and Environmental Research 


\section{DISCLAIMER}

This report was prepared as an account of work sponsored by the U.S. Government. Neither the United States nor an agency thereof, nor any of their employees, makes any warranty, express or implied, or assumes any legal liability or responsibility for the accuracy, completeness, or usefulness of any information, apparatus, product, or process disclosed, or represents that its use would not infringe privately owned rights. Reference herein to any specific commercial product, process, or service by trade name, trademark, manufacturer, or otherwise, does not necessarily constitute or imply its endorsement, recommendation, or favoring by the U.S. Government or any agency thereof. The views and opinions of authors expressed herein do not necessarily state or reflect those of the U.S. Government or any agency thereof. 


\section{Introduction}

The purpose of this report is to provide status of the ingest software used to process instrument data for the Atmospheric Radiation Measurement (ARM) Climate Research Facility (ACRF). The report is divided into four sections: (1) news about ingests currently under development, (2) current production ingests, (3) future ingest development plans, and (4) information on retired ingests. Please note that datastreams beginning in " $\mathrm{xxx}$ " indicate cases where ingests run at multiple ACRF sites, which results in a datastream(s) for each location.

Readers of this status report may want to consult our current list of instrument mentors at http://www.arm.gov/instruments/mentors.php or our list of software developers at http://engineering.arm.gov/engr/task/developercontacts.stm.

Also useful is the current datastream status, presented from the ARM Data Management Facility (DMF) perspective, which can be found at http://c1.dmf.arm.gov/ds/dsview/gui/datastream.php.

Hint: Select the "Login as Guest Account” option. Depending on the speed of your internet connection, it may take a few minutes for the complete display to generate. Datastream status for the current calendar month will be displayed. The legend (visible in the upper right hand area) will help you understand the display. In addition, the number (ideally 24.0) indicates the number of hours of data for the day in question.

For those who are interested in the contents of datastreams generated by ARM software, refer to the data object design files at http://science.arm.gov/tool/dod/showdod.php. 


\section{Contents}

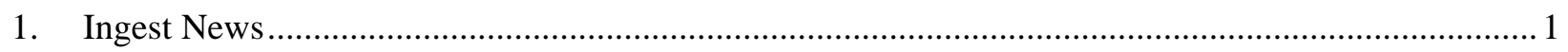

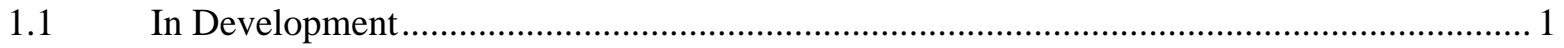

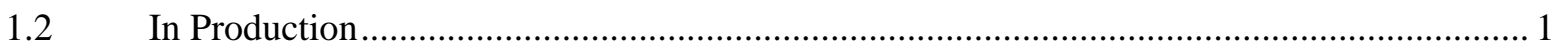

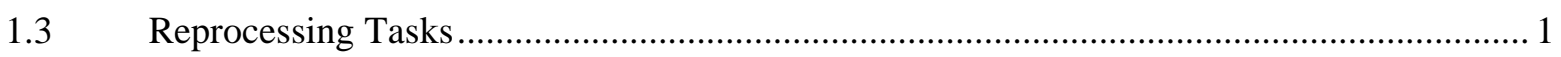

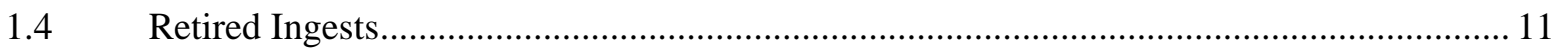

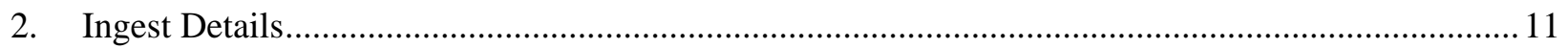

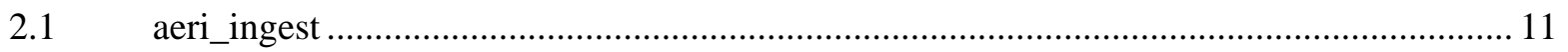

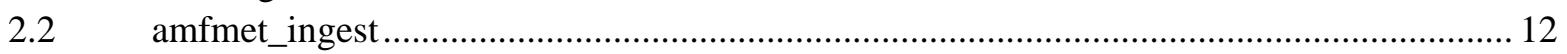

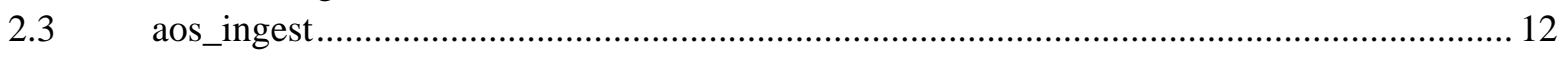

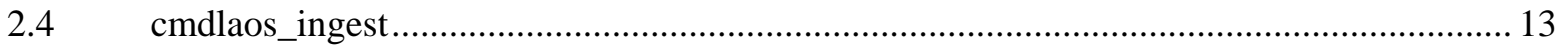

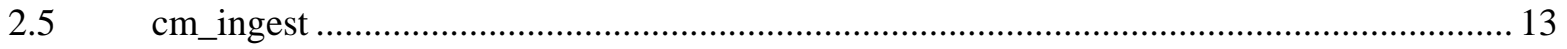

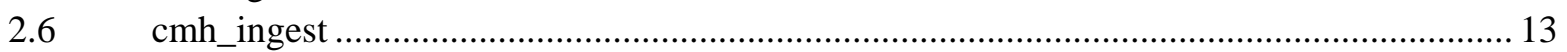

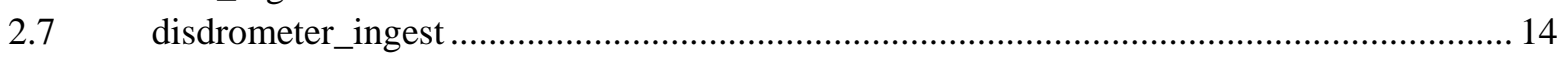

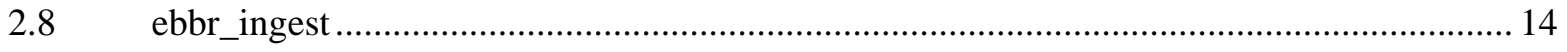

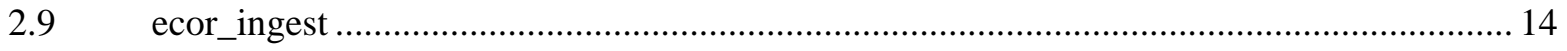

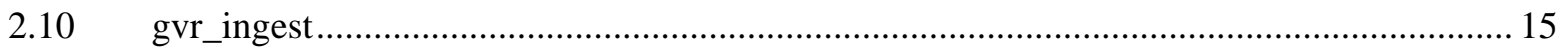

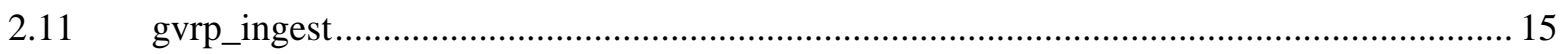

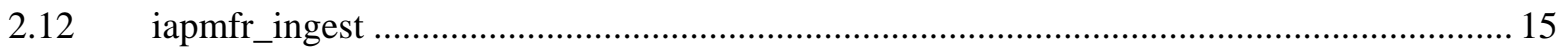

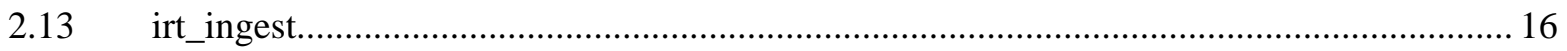

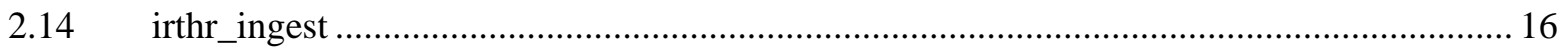

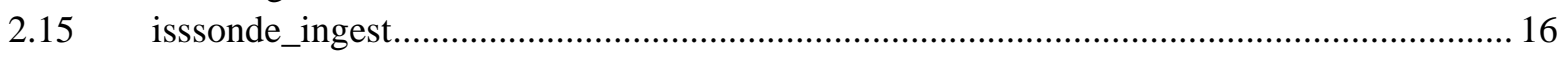

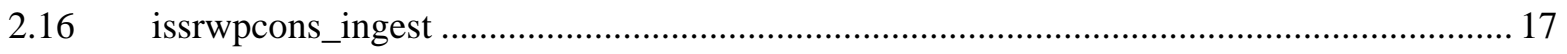

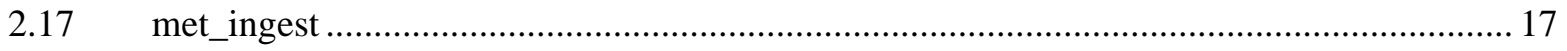

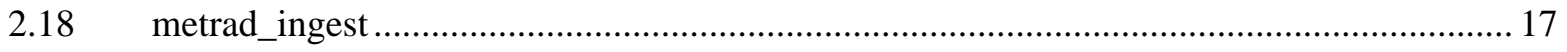

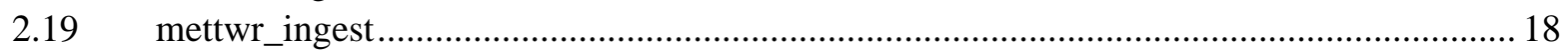

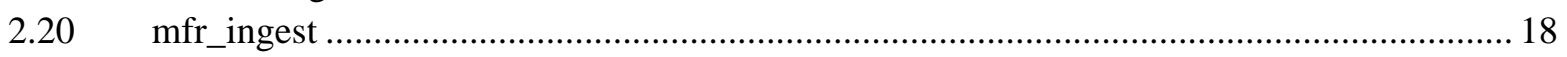

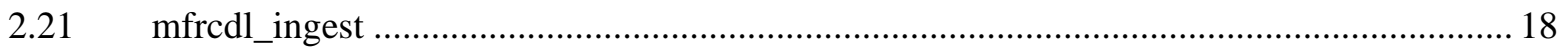

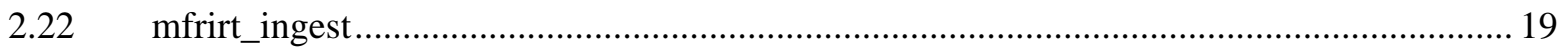

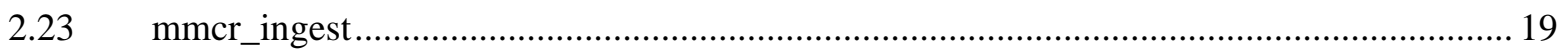

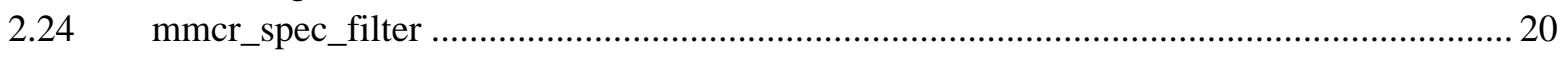

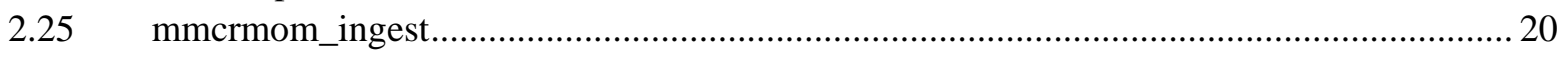

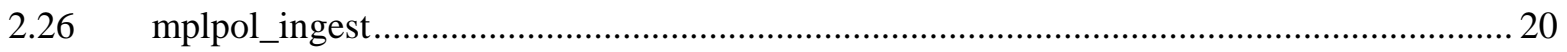

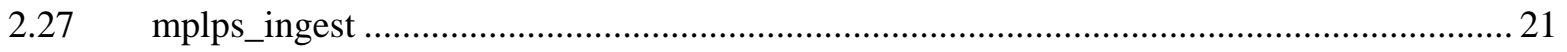

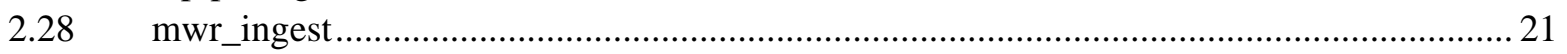

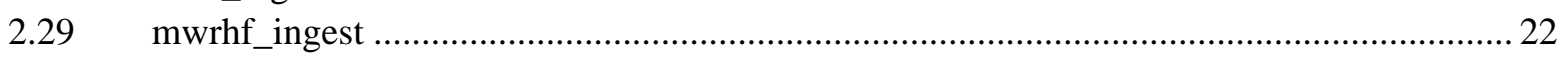

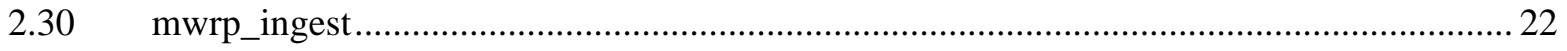

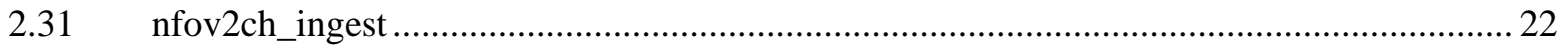

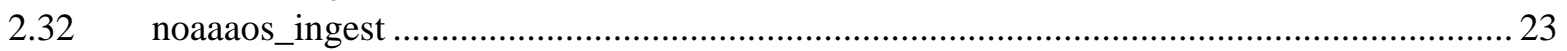

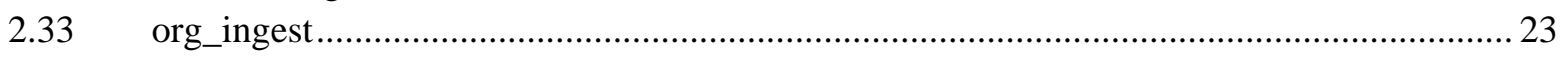

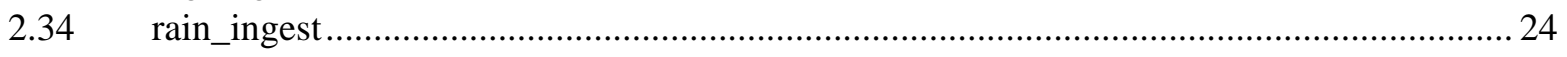

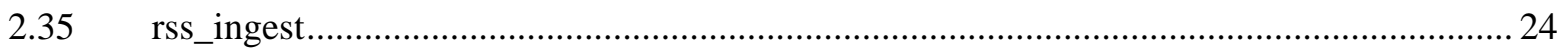

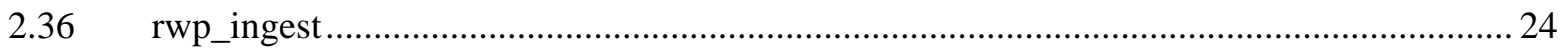

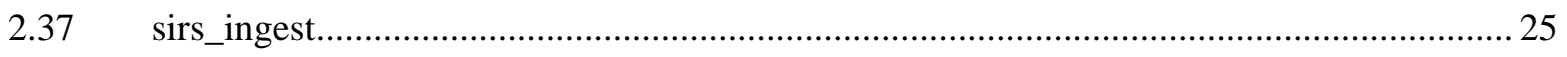




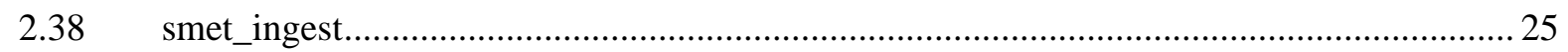

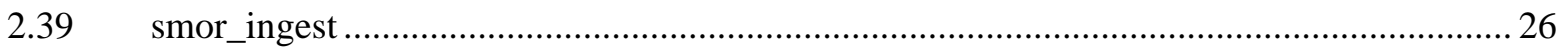

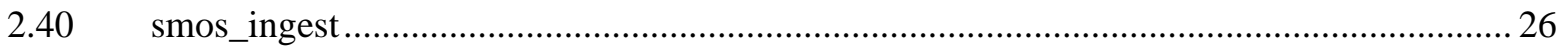

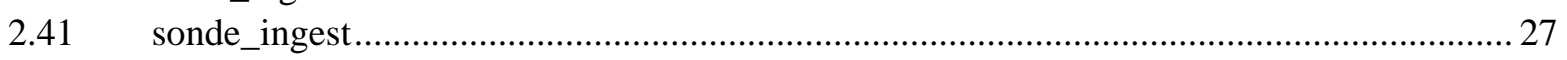

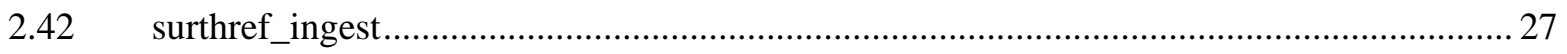

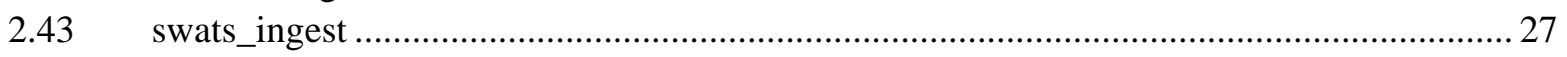

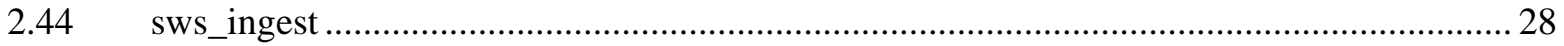

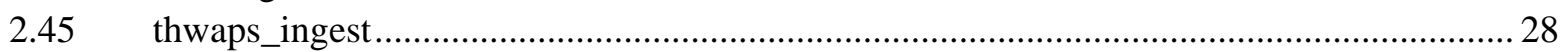

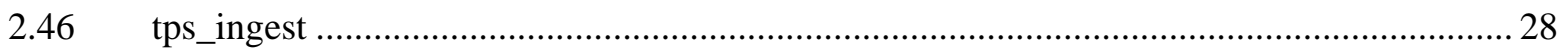

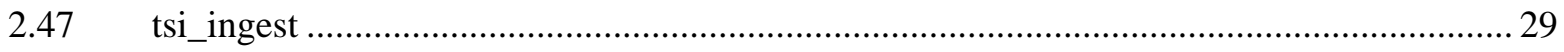

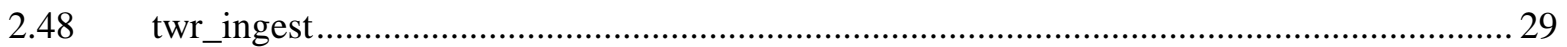

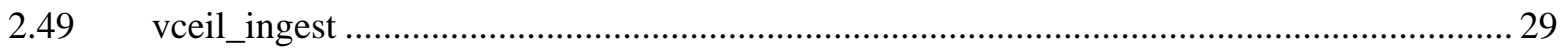

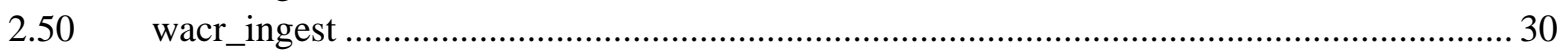

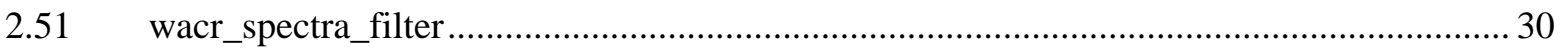

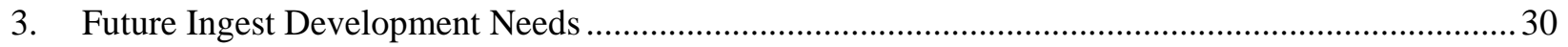




\section{Ingest News}

\subsection{In Development}

We are currently working on the following ingests:

$\underline{\text { mwrhf_ingest }}$

sws_ingest

gvrp ingest

smos_ingest

tps_ingest

\subsection{In Production}

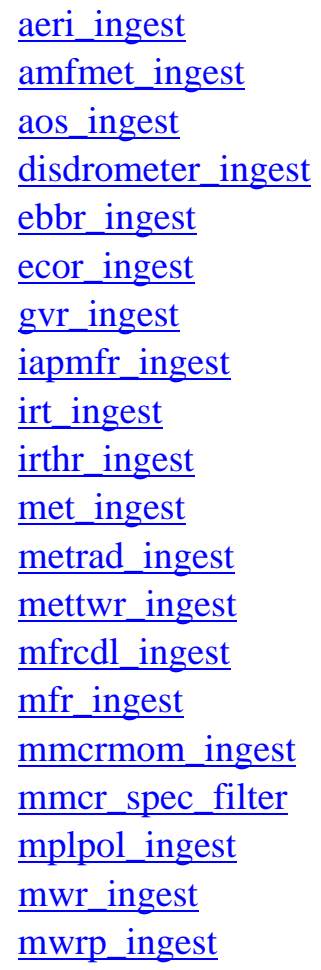

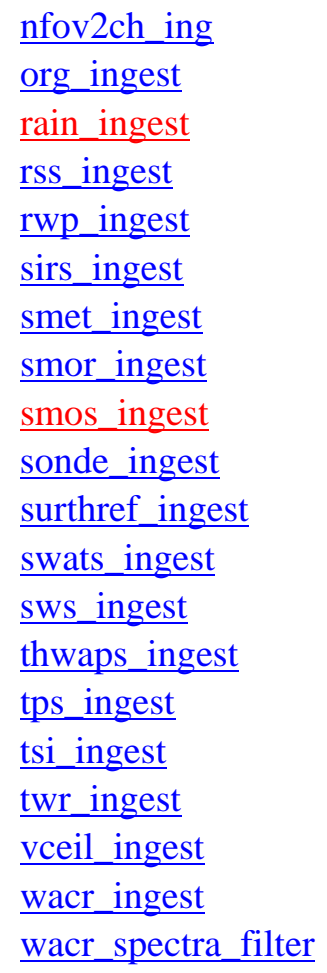

\subsection{Reprocessing Tasks}

The purpose of this section is to present active reprocessing tasks. In some cases, significant software development is required and research into historical calibration records. Reprocessing tasks are identified

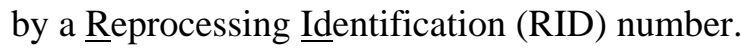

\section{RID-4 SGP.C1 MPL}

Mentor:

Developer:

Reprocessor:

Status:

Date range:
Rich Coulter, ANL Annette Koontz, PNNL Bill Jackson, ORNL Review TBD 


\section{Description:}

The SGP.C1 MPL data for 2000/02/29-2000/03/06 were ingested out of sequence resulting in multiple data files per day. These data were reprocessed by Annette Koontz in October 2007 and she determined for the original processing too many files at one time had been thrown at the ingest. She reprocessed all of 2000 and made those data available to Chaomei Lo (per special request). The data were not archived. Bill Jackson then reprocessed 2000-2003. Waiting on review by Robin Perez.

\section{RID-179 SSS.Fn SIRS/GNDRAD/SKYRAD}

$\begin{array}{ll}\text { Mentor: } & \text { Tom Stoffel, NREL } \\ \text { Developer: } & \text { Brian Ermold, PNNL } \\ \text { Reprocessor: } & \text { Bill Jackson, ORNL } \\ \text { Status: } & \text { On hold pending calibration record review } \\ \text { Date range: } & 2002-2006\end{array}$

\section{Description:}

The longwave calibration procedures were changed in SIRS/GNDRAD/SKYRAD data loggers as early as July 2003. This calibration method change resulted in an error in the longwave data. The previous calibration method was put back into place at all sites by February 2006.

The Solar and Infrared Station (SIRS) data reprocessing is complete. The ARM Mobile Facility (AMF) GNDRAD and SKYRAD reprocessing is complete. The Tropical Western Pacific (TWP) and North Slope of Alaska (NSA) GNDRAD and SKYRAD reprocessing are on hold pending review of calibration records and modification of the old smor_ingest to process the data.

\section{RID-203 SSS.Fn MWR}

Developer: $\quad$ Annette Koontz, PNNL

Reprocessor: $\quad$ Annette Koontz, PNNL, and Bill Jackson, ORNL

Status: $\quad$ Complete: TWP.C1, TWP.C2, NSA.C2, PYE.M1

In process: $\quad$ NSA C1, SGP B1, SGP B4, SGP B5, SGP B6, SGP C1

Date range: $\quad$ end-to-end (through 2005/2006)

\section{Description:}

The MWR retrieval algorithm was modified (most recently) in June 2005. This end-to-end reprocessing of all MWR data will apply the latest retrieval algorithm to all MWR data through time and result in a consistent DOD through time.

The mwr_retrieval software is used to apply a new retrieval to a specific set of days for a specified instrument, as determined by the mentor.

The recalib_mwrlos software is used to apply correct calibrations to the MWRLOS data. It is executed, over a specific set of days for a specified instrument, as determined by the mentor.

In addition, several special purpose scripts are used to reformat the historical MWRLOS data into the current DOD format. These scripts are needed to handle the MWRLOS data for time periods for which the raw data are in an old format, not compatible with the current ingest software. 


\section{RID-307 TWP.Cn/PYE.M1 SMET}

$\begin{array}{ll}\text { Developer: } & \text { Brian Ermold, PNNL } \\ \text { Reprocessor: } & \text { Bill Jackson, ORNL } \\ \text { Status: } & \text { PYE complete; TWP.Cn data 2004-2006 pending review } \\ \text { Date range: } & \text { 1996-2006/07/13 }\end{array}$

\section{Description:}

On 2006/07/13, the units of Barometric pressure data changed from hPa to $\mathrm{kPa}$ to standardize the measurement units among ACRF sites and to conform to accepted standard units determined by the scientific community. Data reprocessing is required to make historical data conform to new units.

NOTE: Reprocessing of old format data (TWP.Cn 1996-2004) will require an ingest update.

\section{RID-312 SSS.Fn MWR-TIP}

Developer:

Reprocessor:

Status:

Date range:
Annette Koontz, PNNL

Annette Koontz, PNNL, and Bill Jackson, ORNL

Waiting for final DOD review by Robin

end-to-end (through March 2007)

Description:

The MWRTIP DOD was modified effective 2007/04/01 to add a tip angle dimension in addition to the time dimension to correct a problem with tip angles being reported out of sequence. This end-to-end reprocessing of all MWRTIP data will result in a consistent DOD through time.

\section{mwrtip retrieval $\quad$ 1.0-0 2008/02/04 per Baseline Change Request (BCR) 1450}

The mwrtip retrieval software is used to apply new retrievals per BCR 984 to MWRTIP data. Most of the historical MWR data requires reprocessing because it has been determined that the retrievals used on the instrument computer were in error. This software applies new retrievals to the MWRTIP data to correct the affected fields. The software has been released into production, but has not been executed yet, pending a final review of the results.

\section{reformat mwrtip $\quad 1.0-0$ 2008/02/04 per BCR 1450}

The reformat_mwrtip software is used to reformat the MWRTIP data per BCR 1385. The historical MWRTIP data are reconstructed to conform to the new DOD structure. After this step is complete, the data may need to be further processed via the mwrtip_retrieval software. The software has been released into production, but has not been executed pending a final review of the results.

\section{RID-352 SSS.Fn MFRSR/MFR10m/MFR25m}

Developer:

Reprocessor:

Status:

Date range:
Annette Koontz, PNNL

Annette Koontz, PNNL

On hold pending calibration records from mentor

end-to-end (through 2007/08/31) 


\section{Description:}

A new method of Multifilter Rotating Shadowband Radiometer (MFRSR) calibration adopted/finalized October 2007 resulted in a new DOD. DMF reprocessed all MFRSR data for all sites beginning 2007/09/01 and all FKB MFRSR data. Historical reprocessing is proceeding (slowly) as the mentor makes available the required calibration records. Complete: NSA.C1, NSA.C2, FKB.M1, SGP.C1, SGP.E13, SGPMFR10m, SGPMFR25m.

Active reprocessing: TWP C1, TWP C2, TWP C3

NOTE: $\mathrm{mfr} 10 \mathrm{~m}$ and $\mathrm{mfr} 25 \mathrm{~m}$ processing is done using prior calibration methods. There has been some talk of converting this processing to the new calibration method, but no work has been done toward that end.

\section{RID-358 SSS.Fn LANGLEY}

$\begin{array}{ll}\text { Developer: } & \text { Annette Koontz, PNNL } \\ \text { Reprocessor: } & \text { Bill Jackson, ORNL } \\ \text { Status: } & \text { Follow-on task to RID-352 } \\ \text { Date range: } & \text { end-to-end }\end{array}$

\section{Description:}

This reprocessing task is to run the Langley Value-added Product (VAP) using new MFRSR and Normal Incidence Multifilter Radiometer (NIMFR) input following RID-352 completion.

Active reprocessing: SGP C1, SGP E13 completed, in review

TWP C1 and TWP C2 being processed

\section{RID-359 SSS.Fn MFRSR-OD}

Developer: $\quad$ Annette Koontz, PNNL

Reprocessor: $\quad$ Bill Jackson, ORNL

Status: $\quad$ Follow-on task to RID-358

Date range: end-to-end

\section{Description:}

This reprocessing task is to run the mfrod1barnmich VAP new Langley and MFRSR/NIMFR input following RID-358 completion.

Active reprocessing: SGP C1, SGP E13 completed, in review

\section{RID-360 SGP.C1 MWRHF}

Developer: $\quad$ Sutanay Choudhury, PNNL

Reprocessor: TBD

Status:

On hold pending resolution of duplicate sample times

Date range: 2006/11/03-2007/04/02 


\section{Description:}

The DOD says pressure is measured in $\mathrm{kPa}$, but data are in $\mathrm{hPa}$. The ingest is being modified to convert the data to $\mathrm{kPa}$. New quality check (QC) limits are also being applied.

\section{RID-365 SSS.Fn QCRad1Long}

Developer: $\quad$ Yan Shi, PNNL

Reprocessor: $\quad$ Yan Shi, PNNL

Status: $\quad$ Recently archived TWP C1, TWP C2, TWP C3, NSA C1, NSA C2

Date range: $\quad$ end-to-end

\section{Description:}

Originally, processed data had frequent NaNs. The VAP is being modified to remove the NaN values.

\section{RID-388 SSS.Fn AOS}

Developer: $\quad$ Annette Koontz, PNNL

Reprocessor: $\quad$ Robin Perez, PNNL (coordinator)

Status: $\quad$ Metadata cleanup

Date range: $\quad$ end-to-end

\section{Description:}

End-to-end reprocessing to result in consistent DOD and datastream naming through time.

\section{RID-402 SSS.Fn NIMFR}

Developer: $\quad$ Annette Koontz, PNNL

Reprocessor: Annette Koontz, PNNL

Status: $\quad$ SGP NIMFR C1 Archived, NSA NIMFR C1 and NSA NIMFR C2 not started

Date range: $\quad$ end-to-end (through 20070831)

\section{Description:}

A new method of Multifilter Radiometer (MFR) calibration adopted/finalized October 2007 resulted in a new DOD. DMF reprocessed all NIMFR data beginning 2007/09/01. SGP.C1 historical reprocessing is complete on reproc1 but is waiting for mentor review before archival.

\section{RID-433 NSA.X1 AOS CCN}

Developer: $\quad$ Annette Koontz, PNNL

Reprocessor: Annette Koontz, PNNL

Status: $\quad$ Completed 2008/01/30

Date range: $\quad$ 2007/09/08

\section{Description:}

Corrupt NSA Aerosol Observing System (AOS) cloud condensation nuclei (CCN) raw data were corrected by the mentor and reprocessed. 


\section{RID-435 FKB.M1 MWRP}

$\begin{array}{ll}\text { Developer: } & \text { Annette Koontz, PNNL } \\ \text { Reprocessor: } & \text { Annette Koontz, PNNL } \\ \text { Status: } & \text { Completed 2008/01/16 } \\ \text { Date range: } & \text { 20070917-20071009 }\end{array}$

\section{Description:}

Recalibration.

Software, recal mwrp, has been written to recalibrate the MWRP data. This software requires occasional modification depending upon the nature of a specific recalibration task.

\section{RID-440 SSS.Fn AOS CCN}

Developer: $\quad$ Annette Koontz, PNNL

Reprocessor: $\quad$ Annette Koontz, PNNL

Status: $\quad$ Completed 2008/01/24

Date range: end-to-end

\section{Description:}

End-to-end reprocessing to is required to correct invalid missing data values in AOS CCN data.

Complete: FKB.M1, NIM.M1, PYE.M1, SGP.C1.

\section{RID-445 PYE.M1 AOS NOAA-FitRH}

Developer: $\quad$ Annette Koontz, PNNL

Reprocessor: Bill Jackson, ORNL

Status: $\quad$ Pending review

Date range: 2005/03/09-2005/09/15

\section{Description:}

Correct error in AOS NOAA-FitRH ingest. Data were processed in January 2008.

\section{RID-446 NIM.M1 AOS NOAA-FitRH}

Developer: $\quad$ Annette Koontz, PNNL

Reprocessor: $\quad$ Bill Jackson, ORNL

Status: $\quad$ On hold pending RID-445 review

Date range: 2005/11/19-2006/12/31

\section{Description:}

Correct error in AOS National Oceanic and Atmospheric Administration (NOAA)-FitRH ingest. Data were reprocessed in December 2007, but another problem was found during data review. Need to rereprocess. 


\section{RID-447 SGP.C1 AOS NOAA-FitRH}

Developer:

Reprocessor:

Status:

Date range:
Annette Koontz, PNNL

Bill Jackson, ORNL

On hold pending RID-445 review

2007/05/19-2007/09/30

\section{Description:}

Correct error in AOS NOAA-FitRH ingest. Data were reprocessed in December 2007, but another problem was found during data review. Need to re-reprocess.

\section{RID-448 FKB.M1 GNDRAD}

Developer: $\quad$ Brian Ermold, PNNL

Reprocessor: $\quad$ Bill Jackson, ORNL

Status: $\quad$ Reprocessed 2008/02/18, pending review

Date range: 2007/05/19-2007/09/30

\section{Description:}

Recalibration. This resulted in two additional sensor recalibrations.

\section{RID-450 NSA.C1 SKYRAD}

Developer:

Reprocessor:

Status:

Date range:

\section{Description:}

Recalibration.

\section{RID-451 NSA.C1 GNDRAD}

Developer:

Brian Ermold, PNNL

Reprocessor: Bill Jackson, ORNL

Status:

Date range:
Brian Ermold, PNNL

Bill Jackson, ORNL

Reprocessed 2008/02/25, pending review

2007/10/03-2007/10/25

\section{Description:}

Recalibration.

\section{RID-457 TWP.C2 GNDRAD}

Developer: $\quad$ Brian Ermold, PNNL

Reprocessor: Bill Jackson, ORNL

Status:

Reprocessed 2008/02/25, pending review

Date range:

2007/11/25-2007/11/30 


\section{Description:}

Recalibration.

\section{RID-458 TWP.C2 SKYRAD}

Developer: $\quad$ Brian Ermold, PNNL

Reprocessor: $\quad$ Bill Jackson, ORNL

Status: $\quad$ Reprocessed 2008/02/25, pending review

Date range: $\quad$ 2007/11/25-2007/11/30

\section{Description:}

Recalibration.

\section{RID-459 NSA.C1 AERI}

Developer: $\quad$ Brian Ermold, PNNL

Reprocessor: $\quad$ Dave Turner, UWisc

Status: $\quad$ Completed 2008/01/09

Date range: $\quad$ 2007/11/01-2007/11/28

\section{Description:}

Recalibration.

\section{RID-462 SGP.C1 AOS CCN}

Developer: $\quad$ Annette Koontz, PNNL

Reprocessor: Annette Koontz, PNNL

Status: $\quad$ Completed 2008/02/01

Date range: 2007/05/30-2007/06/01 $\quad$ 2

\section{Description:}

Corrupt SGP AOS CCN raw data were corrected by the mentor and reprocessed.

\section{RID-465 SSS.Fn SONDE}

$\begin{array}{ll}\text { Developer: } & \text { Annette Koontz, PNNL } \\ \text { Reprocessor: } & \text { Nicole Keck, PNNL } \\ \text { Status: } & \text { Completed 2008/01/24 } \\ \text { Date range: } & \text { 2007/12/17-2008/01/06 }\end{array}$

\section{Description:}

Intermittent reprocessing of sonde data from all sites to correct bad surface measurements of temperature and/or RH. 


\section{RID-466 TWP.C3 MPLPOL}

Developer: $\quad$ Annette Koontz, PNNL

Reprocessor: $\quad$ Nicole Keck, PNNL

Status: $\quad$ Completed 2008/01/11

Date range: 2007/12/11-2007/12/19

\section{Description:}

Reprocessing resulted in some fill values being added so the number of range bins is as expected for the MPLPOLAVG VAP. VAP was post-processed.

\section{RID-467 NSA.C1 AERI}

Developer: $\quad$ Brian Ermold, PNNL

Reprocessor: $\quad$ Dave Turner, UWISC

Status: $\quad$ Reprocessed 2008/02/19; reviewing, questions for mentor

Date range: 2007/12/17-2008/02/13

\section{Description:}

Recalibration.

\section{RID-468 SSS.Fn SONDE}

Developer: $\quad$ Annette Koontz, PNNL

Reprocessor: Nicole Keck, PNNL

Status: $\quad$ Completed 2008/02/06

Date range: 2008/01/11-2008/01/15

\section{Description:}

Intermittent reprocessing of sonde data from all sites to correct bad surface measurements of temperature and/or RH.

\section{RID-470 TWP.C1 SONDE}

Developer: $\quad$ Annette Koontz, PNNL

Reprocessor: $\quad$ Nicole Keck, PNNL

Status: $\quad$ Completed 2008/02/12

Date range: 2007/12/29-2008/01/15

\section{Description:}

Raw TWP.C1 SONDE data were missing wind data. Mentor reprocessed from the binary raw and data were reprocessed. 


\section{RID-472 SSS.Fn SONDE}

Developer: $\quad$ Annette Koontz, PNNL

Reprocessor: $\quad$ Nicole Keck, PNNL

Status: $\quad$ Completed 2008/02/22

Date range: 2008/01/17-2008/01/23

\section{Description:}

Intermittent reprocessing of sonde data from all sites to correct bad surface measurements of temperature and/or RH.

\section{RID-473 SGP.C1 RAIN}

Developer: $\quad$ Sutanay Choudhury, PNNL

Reprocessor: Nicole Keck, PNNL

Status: Hold pending additional ingest updates required

Date range: 20071106-current

\section{Description:}

Ingest updated to properly handle missed raw data files. Data reprocessed 2008/01/31. Ingest is still missing some raw data files and metadata are not being properly filled in netcdf header.

\section{RID-474 PYE.M1 AOS CCN}

Developer: $\quad$ Annette Koontz, PNNL

Reprocessor: $\quad$ Annette Koontz, PNNL

Status: $\quad$ Completed 2008/02/11

Date range: 2005/04/01-2005/04/04

\section{Description:}

Corrupt PYE AOS CCN raw data were corrected by the mentor and reprocessed.

\section{RID-475 SSS.Fn SONDE}

Developer: $\quad$ Annette Koontz, PNNL

Reprocessor: $\quad$ Nicole Keck, PNNL

Status: $\quad$ Completed 2008/02/22

Date range: 2008/01/24-2008/01/30

\section{Description:}

Intermittent reprocessing of sonde data from all sites to correct bad surface measurements of temperature and/or RH. 


\section{RID-480 SSS.Fn SONDE}

Developer: $\quad$ Annette Koontz, PNNL

Reprocessor: $\quad$ Nicole Keck, PNNL

Status: In Process

Date range: 2008/01/31-2008/02/10

\section{Description:}

Intermittent reprocessing of sonde data from all sites to correct bad surface measurements of temperature and/or RH.

\section{RID-481 SSS.Fn SONDE}

Developer: Annette Koontz, PNNL

Reprocessor: Nicole Keck, PNNL

Status: In Process

Date range: 2008/02/15-2008/02/20

\section{Description:}

Intermittent reprocessing of sonde data from all sites to correct bad surface measurements of temperature and/or RH.

\subsection{Retired Ingests}

This section lists ingest software that has been retired from production.

cm_ingest

cmh_ingest

issrwpcons ingest

isssonde_ingest

mfrirt_ingest

mmcr_ingest

mplps ingest

noaaaos_ingest

\section{Ingest Details}

In the following sections, we will provide very basic information about the ingest software currently running in production. We list the mentor, lead developer, backup developer, basic information about the processing done by the ingest, and the current operational status. Detailed instrument information can be found at http://www.arm.gov/instruments/.

\section{1 aeri_ingest}

Mentors:

Dave Turner and Ralph Dedecker, UWISC

Lead Developer:

Brian Ermold, PNNL

Backup Developer:

Sutanay Choudhury, PNNL

Current Version:

8.0-0, 2006/10/31

Status:

Running

Recent BCRs:

1241, 1212, 1202 


\section{Description:}

The aeri_ingest is used to read raw data generated by the Atmospherically Emitted Radiance Interferometer (AERI). The following datastreams are generated:

xxxaerich1Fn.b1, channel 1 data

xxxaerich2Fn.b1, channel 2 data

xxxaeriengineerFn.b1, contains engineering data

xxxaerisummaryFn.b1, summary data

\section{2 amfmet_ingest}

Mentor: $\quad$ Mike Ritsche, ANL

Lead Developer: $\quad$ Sutanay Choudhury, PNNL

Backup Developer: Brian Ermold, PNNL

Current Version: $\quad$ 2.0-0, 2006/09/07

Status: Online

Recent BCRs: $\quad 1395$

\section{Description:}

Database entries were updated.

The amfmet_ingest is used to read raw data generated by the AMF surface meteorology measurements.

The following netCDF (i.e., network common data format) datastream is generated:

xxxmetFn.b1

xxxcmhFn.b1

\section{3 aos_ingest}

Mentor: $\quad$ John Ogren, NOAA

Lead Developer: $\quad$ Annette Koontz, PNNL

Backup Developer: $\quad$ Brian Ermold, PNNL

Current Version: $\quad$ 9.6-0, 2007/11/19

Status: Running

Recent BCRs: $\quad$ 1430, 1374, 1293, 1282

\section{Description:}

A new release of the aos_ingest (BCR 1430) corrects parsing of the missing value codes from NOAA's datastream, xxxaosccnFn.a1.

The following datastreams are generated:

xxxaosFn.a1

xxxaosauxFn.a1

xxxaosccnFn.a1 


\section{4 cmdlaos_ingest}

$\begin{array}{ll}\text { Mentor: } & \text { John Ogren, NOAA } \\ \text { Lead Developer: } & \text { Annette Koontz, PNNL } \\ \text { Backup Developer: } & \text { Brian Ermold, PNNL } \\ \text { Current Version: } & 9.8-0,2008 / 01 / 23 \\ \text { Status: } & \text { Running } \\ \text { Recent BCRs: } & \end{array}$

\section{Description:}

This ingest is run at the XDC to process AOS data that has been quality-checked by the mentor at NOAA. It is used to generate the following datastreams: The cmdlaos_ingest was recently updated to correct $\mathrm{f}(\mathrm{RH})$ logic. The cmdlaos_ingest generates the following datastreams:

xxxnoaaaosFn.b0

xxxnoaaaosavgFn.b0

xxxnoaaaosfitrhFn.b0

\section{5 cm_ingest}

$\begin{array}{ll}\text { Mentor: } & \text { TBD } \\ \text { Lead Developer: } & \text { TBD } \\ \text { Backup Developer: } & \text { TBD } \\ \text { Current Version: } & \text { 7.7-0, 2003/10/09 } \\ \text { Status: } & \text { TBD }\end{array}$

\section{Description:}

The $\mathrm{cm}$ _ingest processed data collected from chilled mirror instrumentation at the Southern Great Plains (SGP) site. It produced the following datastreams:

xxxcmFn.b1

xxxcm25mFn.b1

xxxcm60mFn.b1

\section{6 cmh_ingest}

$\begin{array}{ll}\text { Mentor: } & \text { TBD } \\ \text { Lead Developer: } & \text { TBD } \\ \text { Backup Developer: } & \text { TBD } \\ \text { Current Version: } & \text { 7.5-0, 2003/05/28 } \\ \text { Status: } & \text { TBD }\end{array}$

\section{Description:}

The cmh_ingest processed data collected from chilled mirror hygrometer instrumentation at the NSA Barrow (C1) and Atqasuk (C2) facilities. It produced the following datastreams:

xxxcmhFn.b1 


\section{7 disdrometer_ingest}

Mentor: $\quad$ Mary Jane Bartholomew, Brookhaven National Laboratory (BNL)

Lead Developer: $\quad$ Sutanay Choudhury, PNNL

Backup Developer: Brian Ermold, PNNL

Current Version: $\quad$ 2.1-0, 2007/04/23

Status: Running

Recent BCRs: $\quad$ 1362, 1346, 1251, 1156

\section{Description:}

This ingest was upgraded to handle large files. The disdrometer_ingest is used to read data from disdrometer instruments. Disdrometers are used to collect data from tipping bucket rain gauges. The following netCDF datastreams are generated:

xxxdisdrometerFn.b1

\section{8 ebbr_ingest}

Mentor: $\quad$ David Cook, ANL

Lead Developer: $\quad$ Sutanay Choudhury, PNNL

Backup Developer: Brian Ermold, PNNL

Current Version: $\quad$ 8.1-0, 2006/09/05

Status: Running

Recent BCRs: $\quad$ 1036, 674

\section{Description:}

The ebbr_ingest reads data from the Energy Balance Bowen Ratio (EBBR) system. The following datastreams are generated:

xxx5ebbrFn.b1, 5-minute data

xxx15ebbrFn.b1, 15-minute data

xxx30ebbrFn.b1, 30-minute data

\section{9 ecor_ingest}

Mentor: $\quad$ David Cook, ANL

Lead Developer: $\quad$ Sutanay Choudhury, PNNL

Backup Developer: Brian Ermold, PNNL

Current Version: $\quad$ 8.0-0, 2006/10/25

Status: Running

Recent BCRs: $\quad$ 1352, 1218, 1151, 1039, 1015

\section{Description:}

The ecor_ingest reads data from the Eddy Correlation Flux Measurement System (ECOR) and generates netCDF datastreams, which provide in situ, half-hour measurements of the surface turbulent fluxes of momentum, sensible heat, latent heat, and carbon dioxide. Datastreams generated include the following: 


\subsection{0 gvr_ingest}

Mentor: $\quad$ Maria Cadeddu, ANL

Lead Developer: $\quad$ Annette Koontz, PNNL

Backup Developer: Brian Ermold, PNNL

Current Version: $\quad$ 1.3-0, 2007/02/20

Status: Running

Recent BCRs: $\quad$ 1344, 1338, 1329, 1287, 1255, 1189

\section{Description:}

The gvr_ingest reads data generated by the $183.3 \mathrm{GHz}$ radiometer and generates netCDF datastreams. The G-Band Vapor Radiometer (GVR) is located at the NSA C1 site. Datastreams generated include the following:

xxxgvrFn.a0

xxxgvrFn.b1

\subsection{1 gvrp_ingest}

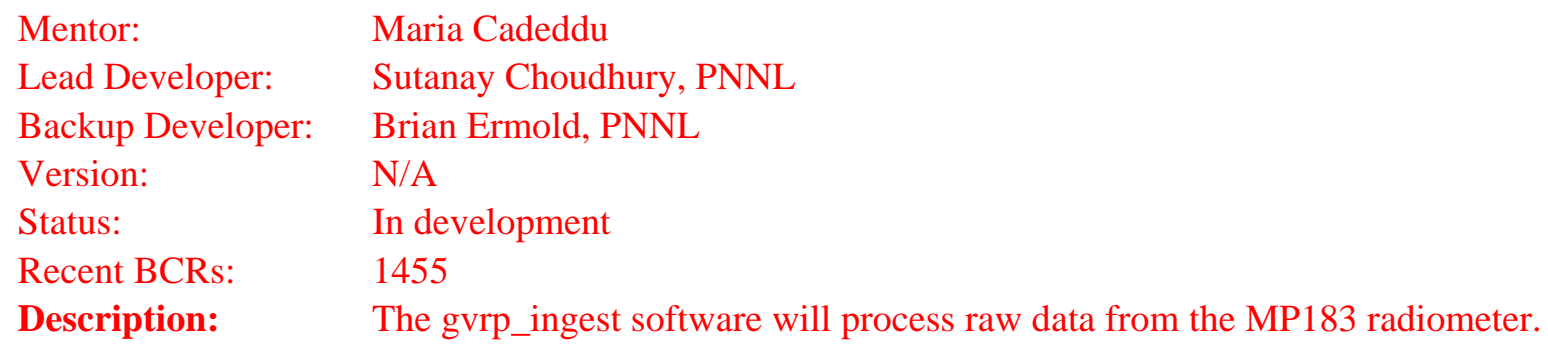

\subsection{2 iapmfr_ingest}

$\begin{array}{ll}\text { Mentor: } & \text { Gary Hodges, NOAA } \\ \text { Lead Developer: } & \text { Annette Koontz, PNNL } \\ \text { Backup Developer: } & \text { Brian Ermold, PNNL } \\ \text { Version: } & 1-2.0,2008 / 01 / 11 \\ \text { Status: } & \text { Running } \\ \text { Recent BCRs: } & 1422-\text { Approved }\end{array}$

\section{Description:}

The datastreams are in final review by the mentor. As soon as the mentor approves the datastream structure, the iapmfr_ingest will be released. In preparation for this release, the zip2tar utility and the preprocess_IAPMFR utility have been released into production. The iapmfr_ingest requires that only the Global Positioning System (GPS) and MFR data be extracted from the In situ Aerosol Profiles (IAP) data. This is done via a combination of the zip2tar and preprocess_IAPMFR software to merge the GPS and MFR data into a single file for each flight.

We expect to generate the following datastream names:

sgpiapmfrC1.a0

sgpiapmfrC1.b1 
Recently updated to trap and correct NaN and Inf values

\subsection{3 irt_ingest}

Mentor: $\quad$ Victor Morris, PNNL

Lead Developer: $\quad$ Brian Ermold, PNNL

Backup Developer: $\quad$ Sutanay Choudhury, PNNL

Current Version: $\quad$ 9.2-0, 2006/10/27

Status: $\quad$ Running

Recent BCRs: $\quad$ 1384, $988,890,777,668$

\section{Description:}

The irt_ingest, similar to the irthr_ingest, reads data from the Infrared Thermometer (IRT) instruments. However, this ingest is designed for the older IRTs that report data every 20 seconds. There is one IRT located on a tower at 10 meters above the ground and another at 25 meters above the ground. The towermounted instruments are pointed downward. Datastreams generated include the following:

xxxirt10mFn.b1, 10-meter tower data

xxxirt25m20sFn.a0. 25-meter tower data, 20-second interval

xxxirt25mFn.b1, 25-meter tower data, 1-minute averages

\subsection{4 irthr_ingest}

Mentor:

Lead Developer:

Backup Developer:

Current Version:

Status:

Recent BCRs:
Victor Morris, PNNL

Sutanay Choudhury, PNNL

Brian Ermold, PNNL

2.0-0, 2006/08/14

Running

1111

\section{Description:}

The irthr_ingest reads data from the high-resolution IRT instruments distributed around the SGP.

Datastreams generated are for 200-millisecond, 2-seconds, and 1-minute sample intervals and include the following:

xxxirt200msFn.a1, 200-millisecond data

xxxirt2sFn.b1, 2-second data

xxxirtFn.b1, 1-minute data

\subsection{5 isssonde_ingest}

Mentor: $\quad$ Barry Lesht, ANL

Lead Developer: $\quad$ Brian Ermold, PNNL

Backup Developer: TBD

Version: $\quad$ 8.0-0, 2007/03/20

Status: $\quad$ Retired ingest being revised for historical data processing

Recent BCRs: $\quad 1337$ 


\section{Description:}

The issonde_ingest development work was completed in March 2007. The data were reprocessed and archived in July 2007. This one should be removed from the "ingests in development" section. The ingest has been retired also.

\subsection{6 issrwpcons_ingest}

$\begin{array}{ll}\text { Mentor: } & \text { TBD } \\ \text { Lead Developer: } & \text { TBD } \\ \text { Backup Developer: } & \text { TBD } \\ \text { Current Version: } & \text { 7.1-0, 2001/02/23 } \\ \text { Status: } & \text { TBD }\end{array}$

\section{Description:}

The issrwpcons_ingest was used to process data from an external rass wind profiler (RWP) located at the TWP. It produced the following datastreams:

xxx915issrwptempconFn.a1

xxx925issrwpwindconFn.a1

\subsection{7 met_ingest}

Mentor: $\quad$ Mike Ritsche, ANL

Lead Developer: $\quad$ Sutanay Choudhury, PNNL

Backup Developer: $\quad$ Brian Ermold, PNNL

Current Version: $\quad$ 7.8-0, 2001/10/20

Status: $\quad$ Running

Recent BCRs: $\quad$ 1335, 1232, 1163, 1059

\section{Description:}

The met_ingest processed data collected from conventional in situ sensors measuring meteorological data such as wind speed, barometric pressure, and so on. The following datastream is generated:

xxxmetFn.b1

\subsection{8 metrad_ingest}

Mentor: $\quad$ Mike Ritsche, ANL

Lead Developer: $\quad$ Sutanay Choudhury, PNNL

Backup Developer: $\quad$ Brian Ermold, PNNL

Current Version: $\quad$ 2.0-0, 2006/10/31

Status: Offline

Recent BCRs: $\quad$ None.

\section{Description:}

The metrad_ingest processes raw radiometer and meteorological data to produce NetCDF files. The following datastreams are generated: 
nimmetS1.b1

nimradS1.b1

\subsection{9 mettwr_ingest}

Mentor: $\quad$ Mike Ritsche, ANL

Lead Developer: $\quad$ Brian Ermold, PNNL

Backup Developer: Sutanay Choudhury, PNNL

Current Version: $\quad$ 2.1-0, 2006/09/08

Status: Running

Recent BCRs: 1133

\section{Description:}

The mettwr_ingest processes data collected from conventional in situ sensors on the ground and on a tower at 10 meters and 40 meters above the ground. The sensors measure meteorological data such as wind speed, barometric pressure, and so on. The mettwr_ingest is used to process data collected at the NSA from surface and tower meteorological instrumentation. Datastreams generated include the following:

xxxmettwr2hFn.b1

xxxmettwr4hFn.b1

xxxmettwrFn.b1

\subsection{0 mfr_ingest}

Mentor:

Lead Developer:

Backup Developer:

Current Version:

Status:

Recent BCRs:
Gary Hodges, NOAA

Annette Koontz, PNNL

Brian Ermold, PNNL

7.19-0, 2006/09/18

Running

1297, 1177, 1145

\section{Description:}

Soon data from the NIMFR will be processed via mfrcdl_ingest. The mfr_ingest is used to process NIMFR, MFR10m, and MFR25m data. The datastreams generated include the following:

xxxmfr10mFn.a0

xxxmfr10mFn.b1

xxxmfr25mFn.a0

xxxmfr25mFn.b1

xxxnimfrFn.a0

xxxnimfrFn.b1

\subsection{1 mfrcdl_ingest}

Mentor:

Lead Developer:

Backup Developer:

Current Version:
Gary Hodges, NOAA

Annette Koontz, PNNL

Brian Ermold, PNNL

9.9-0, 2007/10/08 
Status: $\quad$ Running

Recent BCRs: $\quad$ 1380, 1230

\section{Description:}

Most recently, changes made to the MFRSR processing logic were retracted. Those changes marked data as "missing" that are non-physical. However, those changes caused difficulties for the Data Quality Office software, so they were retracted. Logic to handle the non-physical MFRSR data will be handled eventually via a VAP.

The following datastreams are generated:

xxxmfrsrFn.a0

xxxmfrsrFn.b1, processed data

xxxmfrsrauxFn.a0

Several SGP MFRSRs have been converted to the Campbell Data Logger. Raw data are being collected. We can now process NIMFR data via this ingest.

\subsection{2 mfrirt_ingest}

Mentor: $\quad$ N/A

Lead Developer: $\quad$ Annette Koontz, PNNL

Backup Developer: $\quad$ N/A

Current Version: $\quad$ 8.1-0, 2006/03/06

Status: Offline

\section{Description:}

The mfrirt_ingest was used to process data collected from an IRT instrument that was included in an MFR datastream at SGP C1. It produced the following datastreams:

xxxmfrirt10mFn.b1

xxxmfrirt25mFn.b1

NOTE: These data have all been reprocessed and cloned to look like sgpirt10mC1.b1 and sgpirt25mC1.b1 data.

\subsection{3 mmcr_ingest}

Mentor: $\quad$ N/A

Lead Developer: $\quad$ Annette Koontz, PNNL

Backup Developer: N/A

Current Version: $\quad$ 8.0-0, 2006/11/01

Status: $\quad$ Retired, replaced by mmormom_ingest

\section{Description:}

The mmcr_ingest has been replaced by the mmcrmom_ingest. The mmcr_ingest was used to process data collected from the first generation of Millimeter Wavelength Cloud Radar (MMCR) instruments. It produced the following datastreams: 
xxxmmcrcalFn.a1

xxxmmcrmomentsFn.a1

xxxmmcrmonFn.a1

\subsection{4 mmcr_spec_filter}

$\begin{array}{ll}\text { Mentor: } & \text { Karen Johnson, BNL } \\ \text { Lead Developer: } & \text { Annette Koontz, PNNL } \\ \text { Backup Developer: } & \text { Brian Ermold, PNNL } \\ \text { Version: } & \text { 2.8-0, 2007/10/22 } \\ \text { Status: } & \text { Online at SGP C1 } \\ \text { Recent BCRs: } & 1374\end{array}$

\section{Description:}

Recent changes were implemented to get the filtered data flowing. Currently, this is happening for SGP C1 data only, with filtered spectra data delivered directly to the ACRF Archive. The mentor may be providing logic adjustments to handle thin clouds more effectively in the future.

\subsection{5 mmcrmom_ingest}

Mentor: $\quad$ Kevin Widener, PNNL, and Karen Johnson, BNL

Lead Developer: $\quad$ Annette Koontz, PNNL

Backup Developer: Brian Ermold, PNNL

Current Version: $\quad$ 8.5-1, 2007/06/6

Status: Running

Recent BCRs: $\quad$ 1382, 1203, 918, 899

\section{Description:}

The mmcrmom_ingest has been modified recently to better filter out not-a-number and infinity values. The mmcrmom_ingest is used to process data from the MMCR. Datastreams generated include the following:

\section{xxxmmcrmomFn.b1}

Per Engineering Change Order (ECO) 610, the raw and processed MMCR data will be undergoing another facelift. There is no news on when this will happen, but the Engineering Change Request (ECR) was approved.

\subsection{6 mplpol_ingest}

Mentor: $\quad$ Richard Coulter, ANL

Lead Developer: $\quad$ Annette Koontz, PNNL

Backup Developer: Brian Ermold, PNNL

Current Version: $\quad$ 9.3-1, 2008/01/07

Status: Running

Recent BCRs: $\quad$ 1392, 1315, 1233 


\section{Description:}

The mplpol_ingest processes data from the Micropulse Lidar (MPL). Datastreams generated include the following:

xxxmplpolFn.b1

Since these data are used by several important “downstream” VAPs, a VAP to average the MPLPOL data has been released and is being run on the DMF. The corresponding averaged datastream names are the following:

xxxmplpolavgFn.c1

xxxmplpolavgFn.s1

The mplpol_ingest has been modified to handle fluctuating range-bins recently.

\subsection{7 mplps_ingest}

$\begin{array}{ll}\text { Mentor: } & \text { Richard Coulter, ANL } \\ \text { Lead Developer: } & \text { Annette Koontz, PNNL } \\ \text { Backup Developer: } & \text { Brian Ermold, PNNL } \\ \text { Current Version: } & \text { 8.0-0, 2006/10/27 } \\ \text { Status: } & \text { Retired }\end{array}$

The mplps_ingest was used to process data collected from a prototype, a polarizing MPL, located at the NSA C1. It produced the following datastream:

xxxmplpsFn.a0

These data were subsequently used as input to the mplavg process, which produced

xxxmplFn.a1

and was used as input to the Active Remotely-Sensed Cloud Locations (ARSCL) VAP. This ingest was retired when the mplpol_ingest was put in production at the NSA C1.

\subsection{8 mwr_ingest}

Mentor:

Lead Developer:

Backup Developer:

Current Version:

Status:

Recent BCRs:
Maria Cadeddu, ANL

Annette Koontz, PNNL

Brian Ermold, PNNL

$10.0-0,2007 / 06 / 26$

Running

1385, 1223

\section{Description:}

The mwr_ingest processes data from the Microwave Radiometer (MWR). Datastreams generated include the following: 
xxxmwrlosFn.b1, line-of-sight data

xxxmwrlosFn.a1, TIP data

The format of the MWRTIP files changed because of BCR 1385. The data are being reprocessed so that the MWRTIP files will have a consistent format.

\subsection{9 mwrhf_ingest}

$\begin{array}{ll}\text { Mentor: } & \text { Maria Cadeddu, ANL } \\ \text { Lead Developer: } & \text { Sutanay Choudhury, PNNL } \\ \text { Backup Developer: } & \text { Brian Ermold, PNNL } \\ \text { Version: } & 1.1-0,2007 / 06 / 25 \\ \text { Status: } & \text { Offline } \\ \text { Recent BCRs: } & 1358,1319,1302\end{array}$

\section{Description:}

The mwrhf_ingest processes 90/150-GHz Microwave Radiometer - high frequency (MWRHF) data. This instrument has been installed at the SGP C1 and at the AMF deployment in Germany (FKB M1).

The ingest is being modified to make the file handling logic more robust (EWO 12253).

The following datastreams are generated:

xxxmwrhfFn.b1

\subsection{0 mwrp_ingest}

Mentor:

Lead Developer:

Backup Developer:

Current Version:

Status:

Recent BCRs:
Maria Cadeddu, ANL

Annette Koontz, PNNL

Sutanay Choudhury, PNNL

8.3-0, 2007/09/06

Running

1320, 1314, 1250, 1249, 1234

\section{Description:}

Recent changes were made to remove not-a-number and infinity values. The mwrp_ingest processes data collected from the Microwave Radiometer Profiler (MWRP). Datastreams generated include the following:

xxxmwrpFn.b1

\subsection{1 nfov2ch_ingest}

Mentor: Gary Hodges, NOAA

Lead Developer: $\quad$ Sutanay Choudhury, PNNL

Backup Developer: $\quad$ TBD

Current Version: $\quad$ 11.0-1, 2007/05/01

Status: Running

Recent BCRs: $\quad$ 1286, 1028, 1006 


\section{Description:}

This ingest has been ported to the new database and is currently running for AMF deployment in Germany. The nfov2ch_ingest processes data collected from the Narrow Field of View, 2-channel radiometer (NFOV2).

The following datastream is generated:

xxxnfov2chFn.b1

The mentor indicates that the instrument is out for calibration and/or repair. No estimate is available at this time for its return to production. In addition, the nfov2ch_ingest is being modified to use new databases and a new version will be released prior to the AMF deployment in Germany.

\subsection{2 noaaaos_ingest}

Mentor: $\quad$ John Ogren, NOAA

Lead Developer: $\quad$ Annette Koontz, PNNL

Backup Developer: $\quad$ N/A

Current Version: $\quad$ 2.2-0, 2006/12/22

Recent BCRs: $\quad 1374$

Status: $\quad$ Retired, became aos_ingest

\section{Description:}

The noaaaos_ingest processed raw (not mentor reviewed) data collected from the NSA and the AMF AOS instruments. It produced the following datastreams:

xxxaosFn.a0

xxxaosauxFn.a0

xxxaosccnFn.a0

\subsection{3 org_ingest}

Mentor: $\quad$ Michael Ritsche, ANL

Lead Developer: $\quad$ Sutanay Choudhury, PNNL

Backup Developer: $\quad$ Brian Ermold, PNNL

Current Version: $\quad$ 1.0-0 1007/10/25

Status: $\quad$ Released, Instrument

Recent BCRs: $\quad 1389$

\section{Description:}

The org_ingest processes optical rain gauge measurements. The first version of the org_ingest has been released into production.

Datastreams generated include the following:

xxxorgFn.b1 


\subsection{4 rain_ingest}

$\begin{array}{ll}\text { Mentor: } & \text { Mary Jane Bartholomew, BNL } \\ \text { Lead Developer: } & \text { Sutanay Choudhury, PNNL } \\ \text { Backup Developer: } & \text { Brian Ermold, PNNL } \\ \text { Current Version: } & \text { 3.1-0, 2008/01/30 } \\ \text { Status: } & \text { Running } \\ \text { Recent BCRs: } & 1395,1156\end{array}$

\section{Description:}

The rain_ingest processes tipping bucket measurements. The rain ingest was upgraded to implement a new interpolation algorithm and support a new optical rain gauge instrument (EWO 12168). The upgraded version was released to production.

Datastreams generated include the following:

xxxrainFn.b1

\subsection{5 rss_ingest}

$\begin{array}{ll}\text { Mentor: } & \text { Piotr Kiedron, NOAA } \\ \text { Lead Developer: } & \text { Brian Ermold, PNNL } \\ \text { Backup Developer: } & \text { Sutanay Choudhury, PNNL } \\ \text { Current Version: } & 2.0-0,2006 / 10 / 31 \\ \text { Status: } & \text { Running } \\ \text { Recent BCRs: } & 1143,1104\end{array}$

\section{Description:}

The rss_ingest is used to process data collected from Rotating Shadowband Spectroradiometers (RSSs). The datastreams generated included the following:

xxxrssFn.b1

NOTE: Data are processed every couple of months, when the required inputs arrive.

\subsection{6 rwp_ingest}

$\begin{array}{ll}\text { Mentor: } & \text { Richard Coulter, ANL } \\ \text { Lead Developer: } & \text { Brian Ermold, PNNL } \\ \text { Backup Developer: } & \text { Sutanay Choudhury, PNNL } \\ \text { Current Version: } & \text { 8.1-0, 2007/4/11 } \\ \text { Status: } & \text { Running } \\ \text { Recent BCRs: } & 1353,1246,1186,974\end{array}$

\section{Description:}

The rwp_ingest processes data collected from RWPs. The datastreams generated include the following: 
xxx50rwptempFn.a2

xxx50rwptempconFn.a1

xxx50rwptempmomFn.a0

xxx50rwptempspecFn.a0

xxx50rwpwindconFn.a1

xxx50rwpwindmomFn.a0

xxx50rwpwindspecFn.a0

xxx915rwptempFn.a2

xxx915rwptempconFn.a1

xxx915rwptempmomFn.a0

xxx915rwptempspecFn.a0

xxx915rwpwindconFn.a1

xxx915rwpwindmomFn.a0

xxx915rwpwindspecFn.a0

xxx1290rwpwindconFn.a1

xxx1290rwpwindmomFn.a0

xxx1290rwpwindspecFn.a0

For the next AMF installation, the rwp_ingest will require modification to handle the new configuration of RWP data.

\subsection{7 sirs_ingest}

Mentor: $\quad$ Tom Stoffel, NREL

Lead Developer: $\quad$ Brian Ermold, PNNL

Backup Developer: $\quad$ Sutanay Choudhury, PNNL

Current Version: $\quad$ 10.0-0, 2006/08/31

Status: Running

Recent BCRs: $\quad$ 1080, 1040

\section{Description:}

The sirs_ingest processes data collected from SIRS instruments. Datastreams generated include the following:

xxxsirsFn.b1

xxxsirs20sFn.a0

xxxskyrad60sFn.b1

xxxskyrad20sFn.a0

xxxgndrad60sFn.b1

xxxgndrad20sFn.a0

\subsection{8 smet_ingest}

Mentor: $\quad$ Michael Ritsche, ANL

Lead Developer: $\quad$ Brian Ermold, PNNL

Backup Developer: $\quad$ Sutanay Choudhury, PNNL

Current Version: $\quad$ 8.1-0, 2006/10/04

Status: Running

Recent BCRs: $\quad$ 1213, 1048, 738 


\section{Description:}

The smet_ingest processes data collected from Surface Meteorological Instruments for TWP (SMET). Datastreams generated include the following:

xxxsmet60sFn.b1

\subsection{9 smor_ingest}

Mentor: $\quad$ TBD

Lead Developer: $\quad$ Brian Ermold, PNNL

Backup Developer: Annette Koontz, PNNL

Version: $\quad$ 7.11-0, 2003/10/09

Status: $\quad$ Retired ingest being revised for reprocessing historical data from Sky Radiometers on Stand for Downwelling Radiation (SKYRAD) and Ground Radiometers on Stand for Upwelling Radiation (GNDRAD)

Recent BCRs: $\quad$ 738, 623, 522, 413, 397, 385

\section{Description:}

This ingest has been taken out of retirement. It will be used for reprocessing historical SKYRAD, GNDRAD, and SMET data, but with the addition of logic to use new databases to improve performance and generate new datastreams comparable to those currently being generated by the sirs_ingest. This reprocessing is needed, at least in part, for subsequent processing by one or more VAPs.

The following datastreams will be generated:

xxxskyrad20sFn.a0

xxxskyrad60sFn.b1

xxxgndrad20sFn.a0

xxxgndrad60sFn.b1

xxxsmet60sFn.b1

\subsection{0 smos_ingest}

Mentor: $\quad$ Michael Ritsche, ANL

Lead Developer: $\quad$ Brian Ermold, PNNL

Backup Developer: $\quad$ Sutanay Choudhury, PNNL

Current Version: $\quad$ 8.2-0, 2008/01/23

Status: Running

Recent BCRs: $\quad$ 1298, 1257, 1178

\section{Description:}

The smos_ingest processes data from the Surface Meteorological Observation System (SMOS)

instruments. The ingest was updated to support new calibration variables and the changes were released to production. Datastreams generated include the following:

xxx1smosFn.b1

xxx30smosFn.b1 


\subsection{1 sonde_ingest}

Mentor:

Barry Lesht, ANL

Lead Developer:

Annette Koontz, PNNL

Backup Developer:

Brian Ermold, PNNL

Current Version:

8.1-0, 2006/09/28

Status:

Running

Recent BCRs:

1245, 1229

\section{Description:}

The sonde_ingest processes data collected from Balloon-Borne Sounding System (sonde). Datastreams generated include the following:

xxxsondewnpnFn.b1

\subsection{2 surthref_ingest}

$\begin{array}{ll}\text { Mentor: } & \text { Michael Ritsche, ANL } \\ \text { Lead Developer: } & \text { Sutanay Choudhury, PNNL } \\ \text { Backup Developer: } & \text { Brian Ermold, PNNL } \\ \text { Current Version: } & \text { 2.0-0, 2006/11/01 } \\ \text { Status: } & \text { Running } \\ \text { Recent BCRs: } & 1124,1106\end{array}$

\section{Description:}

The surthref_ingest processes data collected from Surface Temperature and Humidity Reference (SURTHREF) system instruments. Datastreams generated include the following:

xxxsurthrefFn.b1

\subsection{3 swats_ingest}

$\begin{array}{ll}\text { Mentor: } & \text { John Harris, CIMMS } \\ \text { Lead Developer: } & \text { Brian Ermold, PNNL } \\ \text { Backup Developer: } & \text { Sutanay Choudhury, PNNL } \\ \text { Current Version: } & 10.0-0,2006 / 09 / 07 \\ \text { Status: } & \text { Running } \\ \text { Recent BCRs: } & 1017,896\end{array}$

\section{Description:}

The swats_ingest processes data collected from the Soil Water and Temperature System (SWATS). Datastreams generated include the following:

xxxswatsFn.b1

xxxswatsspcpFn.b1 


\subsection{4 sws_ingest}

$\begin{array}{ll}\text { Mentor: } & \text { Alan Scott Kittelman, CU-Boulder } \\ \text { Lead Developer: } & \text { Sutanay Choudhury, PNNL } \\ \text { Backup Developer: } & \text { Brian Ermold, PNNL } \\ \text { Current Version: } & 3.0-0,2007 / 03 / 06 \\ \text { Status: } & \text { Running } \\ \text { Recent BCRs: } & 1406,1347,1288,1216\end{array}$

\section{Description:}

The sws_ingest is being modified to handle new calibration logic. More enhancements are expected in November 2007. The sws_ingest processes data collected from the Shortwave Spectroradiometer (SWS). Datastreams generated include the following:

xxxswsFn.b1

xxxswsauxFn.b1

\subsection{5 thwaps_ingest}

Mentor: $\quad$ Michael Ritsche, ANL

Lead Developer: $\quad$ Brian Ermold, PNNL

Backup Developer: $\quad$ Sutanay Choudhury, PNNL

Current Version: $\quad$ 8.0-0, 2006/08/14

Status: Running

Recent BCRs: $\quad 726$

\section{Description:}

The thwaps_ingest processes data collected from Temperature, Humidity, Wind, and Pressure Sensors (THWAPS) instruments. Datastreams generated include the following:

xxxthwapsFn.b1

\subsection{6 tps_ingest}

Mentor: $\quad$ Mark Ivey, SNL

Lead Developer: $\quad$ Sutanay Choudhury, PNNL

Backup Developer: $\quad$ Brian Ermold, PNNL

Version:

$1.0-0,2006 / 12 / 22$

Status: Running

Recent BCRs: $\quad$ 1387, 1366

\section{Description:}

The Total Precipitation Sensor (TPS) will be deployed soon at both NSA sites in Barrow and Atqasuk. The tps_ingest will process data from the Total Precipitation Sensor (precipitation rate and daily accumulated precipitation).

xxxtpsFn.b1 


\subsection{7 tsi_ingest}

Mentor:

Lead Developer:

Backup Developer:

Current Version:

Status:

Recent BCRs:
Victor Morris, PNNL

Sutanay Choudhury, PNNL

Brian Ermold, PNNL

10.1-0, 2006/11/07

Running

1294, 1247, 1206, 1107

\section{Description:}

The tsi_ingest processes data collected from the Total Sky Imager (TSI). Datastreams generated include the following:

xxxtsicldmaskFn.a1

xxxtsimovieFn.a

xxxtsiskycoverFn.b1

xxxtsiskyimageFn.a1

\subsection{8 twr_ingest}

$\begin{array}{ll}\text { Mentor: } & \text { David Cook, ANL } \\ \text { Lead Developer: } & \text { Brian Ermold, PNNL } \\ \text { Backup Developer: } & \text { Sutanay Choudhury, PNNL } \\ \text { Current Version: } & 8.0-0,2006 / 09 / 07 \\ \text { Status: } & \text { Running } \\ \text { Recent BCRs: } & 727\end{array}$

\section{Description:}

The twr_ingest processes data collected from meteorological instruments located on towers above the ground. The datastreams generated include the following:

xxx1440twr21xFn.b1

xxx1440twr25mFn.b1

xxx1440twr60mFn.b1

xxx1twr10xFn.b1

xxx1twr25mFn.b1

xxx1twr60mC1.b1

xxx30twr10xFn.b1

xxx30twr25mFn.b1

xxx30twr60mFn.b1

\subsection{9 vceil_ingest}




\section{Description:}

The vceil_ingest processes data collected from Vaisala Ceilometers (VCEILs). Datastreams generated include the following:

xxxvceil25kFn.b1

\subsection{0 wacr_ingest}

Mentor: $\quad$ Kevin Widener, PNNL

Lead Developer: $\quad$ Annette Koontz, PNNL

Backup Developer: $\quad$ Brian Ermold, PNNL

Current Version: $\quad$ 8.1-0, 2006/09/11

Status: Running

Recent BCRs: $\quad$ 1357, 1263, 1242

\section{Description:}

The wacr_ingest processes data collected from W-Band (95-GHz) ARM Cloud Radar (WACR) instruments. Datastreams generated include the following:

xxxwacrFn.b1

\subsection{1 wacr_spectra_filter}

Mentor: $\quad$ Karen Johnson, BNL

Lead Developer: $\quad$ Annette Koontz, PNNL

Backup Developer: $\quad$ Brian Ermold, PNNL

Version: $\quad 3.5-0,2007 / 12 / 31$

Status: Installed

Recent BCRs: $\quad 1349$

\section{Description:}

This ingest was tested on the AMF while it was operating in Germany and briefly at SGP C1. Hardware issues at SGP and at the AMF have been resolved, at least for now. We will begin shipping spectra data to the ACRF Archive soon. The software will be used to generate spectra files that will be shipped directly to the Archive.

\section{Future Ingest Development Needs}

In the next few weeks, the underlying libraries used by the ingests will be updated to further standardize the QC results and make QC attributes more consistent with recent VAP QC standards.

In future months, the latest generation of database software used by the ingest software will continue to be developed. 